\title{
New way of cooling by desiccant cooling system
}

Akanksha Tiwari, Shraddha Sahu, Yogesh Kumar and Soumitra Tiwari

Received : 10.04.2018; Accepted : 13.04.2018

See end of the Paper for authors' affiliation

Correspondence to :

Akanksha Tiwari Department of Food Processing and Technology, Bilaspur University, Bilaspur (C.G.) India
- Abstract : Desiccant cooling system is one of the options in our daily life to provide the best indoor air quality and thermal comfort with the minimum consumption of energy. In cooling systems a solid desiccant or a liquid desiccant solution can be used to assist in the cooling process. Desiccant has a property of regeneration so it can be recirculated and reused. In this cooling system we use liquid $\mathrm{CO}_{2}$ /dry ice to achieve the sensible heat reduction while using silica gel(desiccant) to absorb moisture and decrease latent heat.The desiccant systems are reasonablypriced, produce no CFCs, and capable of both drying and filtering the air. They provide an opportunity to control humidity and temperature independently, and have the capability of using low quality thermal energy. The performance of the system is evaluated using Cooling Capacity (CC) parameter. The system under a typical summer day of hot and humid climate was tested. A remarkable decrease about $40-65 \%$ in the specific humidity and with a supply air temperature lower than $25^{\circ} \mathrm{C}$ of the proposed system was observed. The study is important and helpful to improve the effectiveness of this kind of liquid desiccant system in hot and humid places.

- Key words : Desiccant cooling, Solid desiccant, Liquid desiccant, Humidity, Temperature

- How to cite this paper : Tiwari, Akanksha, Sahu, Shraddha, Kumar, Yogesh and Tiwari, Soumitra (2018). New way of cooling by desiccant cooling system. Internat. J. Agric. Engg., 11(Sp. Issue) : 76-80, DOI: 10.15740/HAS/IJAE/11.Sp. Issue/76-80. 